\title{
Atmospheric freshwater fluxes and their effect on the global thermohaline circulation
}

\author{
Fritz Zaucker ${ }^{1}$, Thomas F. Stocker ${ }^{2}$ and Wallace S. Broecker ${ }^{3}$ \\ Lamont-Doherty Earth Observatory, Columbia University, Palisades, New York
}

\begin{abstract}
Atmospheric water vapor fluxes were derived from a 1-year data set of horizontal wind speed and specific humidity assimilated from meteorological observations by the European Center for Medium-Range Weather Forecast (ECMWF). Vertically integrated horizontal freshwater fluxes were compared to those of two data sets based on a climatology [Oort, 1983] and on simulations with an atmospheric general circulation model (AGCM). Zonal transports agree fairly well at all latitudes outside the tropics, where fluxes are about double for the AGCM data set. Meridional fluxes of the AGCM and ECMWF data sets show close agreement, while the climatological fluxes are generally smaller with a considerable northward shift in the southern hemisphere. Atmosphere-to-ocean freshwater fluxes were derived from the three data sets. Not only is there substantial disagreement between the data sets, but their zonal averages over the Atlantic, Pacific, and Indian Ocean basins show little resemblance to the respective restoring freshwater fluxes from a 2-dimensional ocean model. If the ocean model is forced with the observed and modeled atmospheric fluxes, we find that the mode of ocean circulation is determined mostly by the net flux to the high-latitude oceans and the amount of freshwater exported from the Atlantic basin. The latitudinal structure of the freshwater fluxes in low-latitudes and midlatitudes has little influence on the modeled thermohaline circulation. The fluxes derived from the climatology and ECMWF permit North Atlantic Deep Water (NADW) formation, but a strong freshwater input to the Southern Ocean inhibits Antarctic Bottom Water formation. The AGCM transports so much moisture to the Arctic Ocean that NADW formation is shut down, resulting in a ocean circulation mode of southern sinking in all three ocean basins. If NADW is formed in the model, the strength of the Atlantic meridional overturning is determined by the net freshwater export from the Atlantic basin. When this export is artificially increased in the model over a range from 0.2 to $1 \mathrm{~Sv}$, the ratio of overturning to freshwater forcing decreases almost linearly.
\end{abstract}

\section{Introduction}

The ocean influences the Earth's climate through the storage and redistribution of sensible and latent heat and, in a more indirect way, through acting as a reservoir for climate relevant substances like $\mathrm{CO}_{2}$ and other greenhouse gases. Because of its large heat capacity it moderates surface air temperature on a diurnal timescale as well as on seasonal and decadal timescales.

\footnotetext{
${ }^{1}$ Formerly also at Institute for Environmental Physics, University of Heidelberg, Germany. Now at Department of Applied Physics, Columbia University, New York.

${ }^{2}$ Now at Physics Institute, University of Bern, Switzerland.

${ }^{3}$ Also at Department of Geology, Columbia University, New York.
}

Copyright 1994 by the American Geophysical Union.

Paper number 94JC00526.

0148-0227/94/94JC-00526\$05.00
The global thermohaline circulation redistributes heat in the world ocean like a "conveyor belt" [Broecker, 1991]. This is especially pronounced in the North Atlantic, where large amounts of heat are transported northward and reduce the latitudinal temperature gradient, resulting in much higher winter temperatures in Europe than at corresponding latitudes elsewhere. The thermohaline circulation is mainly driven by the production of cold and saline water in the northern North Atlantic as first described by Wüst [1935] and Wüst and Defant [1936]. In the Atlantic Ocean the upper limb of the conveyor runs from south to north. It is relatively warm and becomes enriched in salinity by the excess of evaporation over precipitation on its way through the subtropical latitudes. This salt enrichment outweighs the dilution in the rain belts of the intertropical convergence zone (ITCZ) and the midlatitudes and high latitudes. The surface water is cooled in the northern Atlantic by the release of sensible and latent heat (the latter being the dominating factor according to War- 
ren [1983] and thus maintaining a relatively high salinity). It is further enriched in salinity by brine release during sea ice formation. When the density of the upper layers exceeds that of the underlying water masses the water column becomes unstable, and by convective overturning (mostly in the Greenland, Norwegian, and Labrador Seas) deep waters are formed which eventually contribute significantly to North Atlantic Deep Water (NADW). The latter forms the lower limb of the conveyor belt, running southward through the Atlantic Ocean. For a more complete discussion of the conveyor belt see for example Gordon [1986] and Broecker [1991]. As winter sea surface temperatures (SSTs) are similar at corresponding latitudes, the asymmetry with deep water formation in the North Atlantic and upwelling in the Pacific is probably related to the different salinity distribution in the two oceans. Surface salinity is higher in the Atlantic Ocean by about $1 \%$ on average and up to $2-3 \%$ higher in northern latitudes [Levitus, 1982]. This salinity distribution is linked to the imbalance of evaporation, precipitation, and runoff, which provides the coupling of the transports of salt through the sea and of water vapor through the atmosphere [Stommel, 1980; Stommel and Csanady, 1980; Warren, 1983; Gordon and Piola, 1983]. Thus the thermohaline circulation could be strongly affected by changes of the atmospheric water vapor transport within and between ocean basins [Broecker et al., 1990; Stocker and Wright, 1991; Zaucker and Broecker, 1992].

The importance of the thermohaline circulation to climate was first recognized by Chamberlin [1906], who discussed whether ice age cycles might be due to changes in the deep ocean circulation. This was carried further by Weyl [1968] and Walin [1985]. Since then, many studies have proposed changes in the thermohaline circulation as a cause for the rapid climate changes reported in Greenland ice cores [e.g., Dansgaard et al., 1989] and supported by observational evidence from deep-sea sediment cores [e.g., Lehman and Keigwin, 1992]. Broecker and Denton [1989] have summarized paleoclimatic information and postulate that glacial to interglacial transitions are associated with reorganizations in the ocean, atmosphere, and cryosphere.

Variability on a short timescale is also detected in the present-day ocean, at least on a regional scale. Using tritium; ${ }^{\mathbf{3}} \mathrm{He}$, and freon data from the Greenland Sea, Schlosser et al. [1991] estimate that deepwater formation was reduced by about $80 \%$ in this area in the 1980 s. They hypothesize that this change might be linked to the salinity anomaly in the northern North Atlantic observed by Dickson et al. [1988]. The importance of the atmosphere-to-ocean freshwater fluxes to the thermohaline circulation was also demonstrated in threedimensional ocean models [e.g., Bryan, 1986; MaierReimer and Mikolajewicz, 1989; Marotzke and Willebrand, 1991; Weaver et al., 1993] and coupled models [e.g., Manabe and Stouffer, 1988].

In this paper we assess the compatibility of observed and modeled atmospheric water vapor fluxes with the formation of NADW. For this purpose we present zon- ally averaged atmospheric water vapor fluxes and flux convergences derived from observations and the atmospheric general circulation model (AGCM) developed at Goddard Space Flight Center, Institute for Space Studies (GISS). It should be noted that the dataderived fluxes are not direct observations, but rather derived quantities from observations of other meteorological variables. For simplicity we will nevertheless use the word observations but one should keep in mind that the database from which the fluxes were calculated is sparse over large areas of the globe and that either mathematical interpolation or meteorological models were used to achieve a global data set. We compare the atmospheric fluxes with each other and with those diagnosed from a two-dimensional ocean model forced with observed surface temperature and salinity. We further investigate the compatibility of the atmospheric fluxes with the thermohaline circulation of the ocean model.

The link between the Atlantic Ocean's freshwater balance and the strength of the meridional overturning is schematically explained in Figure 1. For simplicity we consider the Atlantic and Pacific as representative of two fundamentally different basins of the world ocean. The thermohaline circulation constitutes the lower branch of the global hydrological cycle: In the modern Atlantic, about $20 \mathrm{~Sv}\left(1 \mathrm{~Sv}=10^{6} \mathrm{~m}^{3} / \mathrm{s}\right)$ of water with an excess salinity of about $+0.6 \%$ is exported by NADW (a mean ocean salinity of $35 \%$ is assumed). The upper ocean return flow is close to this mean salinity. At steady state the salt loss must be compensated by a net loss of freshwater (salinity excess $-35 \%$ ) through the surface of the Atlantic. A mass flux of $20 \mathrm{~Sv}$ in the ocean can thus be balanced by an atmospheric freshwater loss from the Atlantic drainage basin of only about $0.4 \mathrm{~Sv}$. If atmospheric freshwater export is a forcing function of the "conveyor belt", then a small change in the atmospheric water vapor transport could result in a major change in ocean circulation. On the basis of the above estimates one can derive an amplification factor of about $20 / 0.4=50$. Earlier modeling results confirm the sensitivity of the ocean circulation to changes in the atmospheric branch of the hydrological cycle [Stocker and Wright, 1991]. Freshwater forcing is not the only driving mechanism for NADW formation. For example, high-latitude heat loss from the ocean to

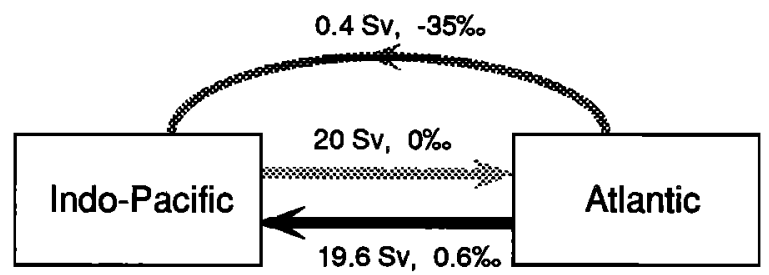

Figure 1. The importance of small changes of the atmospheric water vapor fluxes to the ocean circulation is illustrated by considering both branches of the hydrological cycle. A small atmospheric water vapor (AWV) flux with a highsalinity anomaly balances a strong oceanic transport (NADW) with a small salinity difference. 
the atmosphere is required to achieve the high-density surface water leading to deepwater formation.

The paper is organized as follows: In section 2 of the paper we compare zonal and meridional water vapor fluxes and divergences from the three data sets. The ocean model and the steady state circulations are discussed in section 3 . Section 4 presents sensitivity experiments addressing stability and multiple equilibria of the thermohaline circulation (THC). Discussions follow in section 5 .

\section{Atmospheric Water Vapor Fluxes}

Atmospheric water vapor transport was calculated using the horizontal winds and humidity of various data sets. In the discrete coordinate system of the gridded data we have

$$
\mathbf{Q}_{i j l}=\frac{1}{g} q_{i j l} \mathbf{u}_{i j l} \Delta p_{l}
$$

with water vapor flux $\mathbf{Q}=\left(Q^{\lambda}, Q^{\phi}\right)$ and zonal and meridional water vapor fluxes $Q^{\lambda}$ and $Q^{\phi}$ (in kilograms per meter per second); the gravity constant $g=9.81 \mathrm{~m} \mathrm{~s}^{-2}$; $q$ is specific humidity (in $\mathrm{kg}_{\text {water }} / \mathrm{kg}_{\text {air }}$ ); $\mathbf{u}=(u, v)$ is the horizontal wind with zonal and meridional wind velocities $u$ and $v$ (in meters per second); $i, j$, and $l$ are longitude, latitude, and pressure level indices, respectively; and $\Delta p_{l}$ is the pressure difference between the top and the bottom of the layer (in newtons per square meter). Yearly averaged data will be presented in this study.

In the AGCM runs the fluxes were calculated at each grid box and for each time step (every 15 minutes) and averaged over a month. The model was described in detail by Hansen et al. [1983]. Calculations were done on a regular grid with a horizontal resolution of $4^{\circ} \times 5^{\circ}$ latitude by longitude and nine vertical levels ( $\sigma$ coor- dinates). For the ECMWF analysis, monthly integrals were calculated from the available 6-hourly values for the time period from June 1989 to May 1990. Calculations were done with a $1^{\circ} \times 1^{\circ}$ resolution and 19 vertical model levels (hybrid $\sigma /$ pressure coordinates). To enable comparison the data was then averaged to the $4^{\circ} \times 5^{\circ}$ grid of the AGCM. From a climatology for the years 1963 to 1973 [Oort, 1983] monthly integrated fluxes were calculated as the sum of the monthly means and transient eddies $(\overline{\mathbf{u}} \bar{q}+\overline{\mathbf{u} / q \prime})$; see also Zaucker and Broecker [1992]. The resolution was $5^{\circ} \times 2.5^{\circ}$ latitude by longitude and 11 pressure levels. These fluxes were interpolated to the $4^{\circ} \times 5^{\circ}$ AGCM grid.

Because we use a zonally averaged ocean model to study the impact of atmospheric freshwater transport on the thermohaline ocean circulation, we introduce zonally averaged and vertically integrated atmospheric fluxes according to

$$
\begin{aligned}
& \hat{\mathbf{Q}}_{i j}=\left(\hat{Q}_{i j}^{\lambda}, \hat{Q}_{i j}^{\phi}\right)=\sum_{l=1}^{L}\left(Q_{i j l}^{\lambda}, Q_{i j l}^{\phi}\right) \\
& \tilde{\mathbf{Q}}_{j}=\left(\tilde{Q}_{j}^{\lambda}, \tilde{Q}_{j}^{\phi}\right)=\frac{1}{M} \sum_{i=1}^{M}\left(\hat{Q}_{i j}^{\lambda}, \hat{Q}_{i j}^{\phi}\right) .
\end{aligned}
$$

Q is the (column) water vapor flux integrated over $L$ layers, and $\tilde{\mathbf{Q}}$ is its zonal average over $M$ longitudinal indices. A more detailed discussion of the threedimensional atmospheric transport is given by Zaucker and Broecker [1992] and Zaucker [1992].

\subsection{Zonal and Meridional Fluxes}

In Figure 2 the vertically integrated and zonally averaged zonal water vapor fluxes $\left(\tilde{Q}^{\lambda}\right.$ as defined in (3)) from the observations and from the AGCM run are shown. The agreement between Oort's [1983] climato-

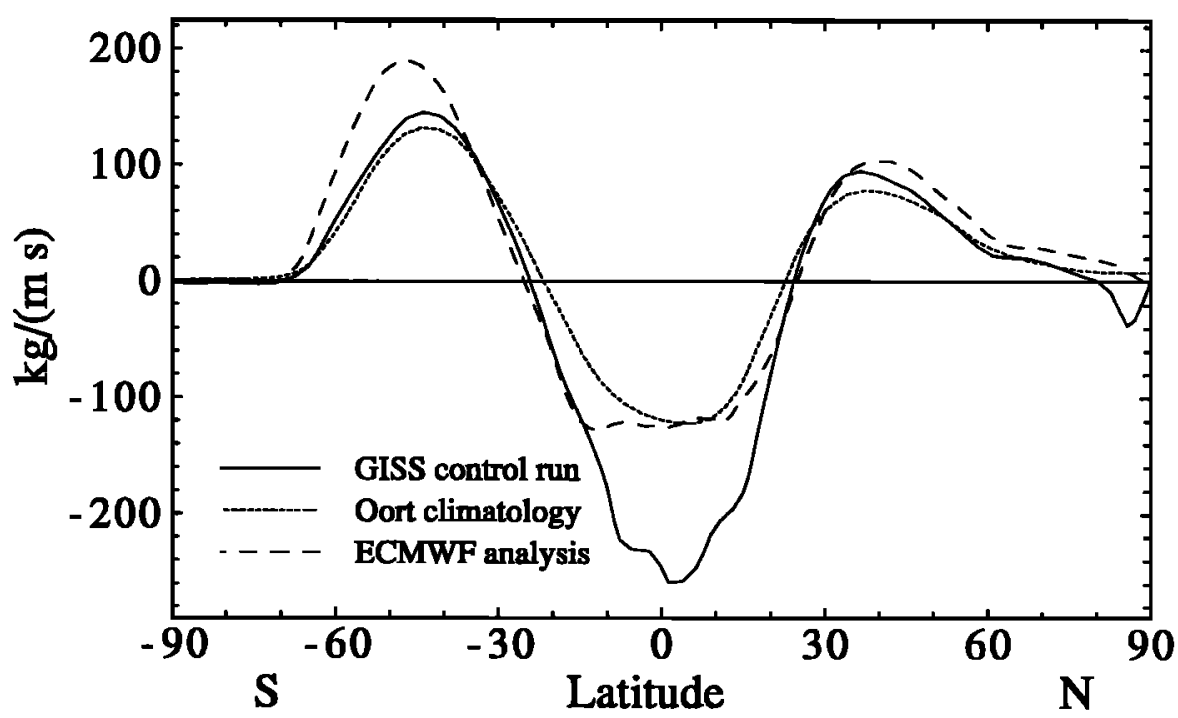

Figure 2. Zonally averaged, vertically integrated zonal water vapor transport for the climatology (dotted line), ECMWF analysis (dashed line) and the AGCM run (solid line). Positive values denote eastward transport. 


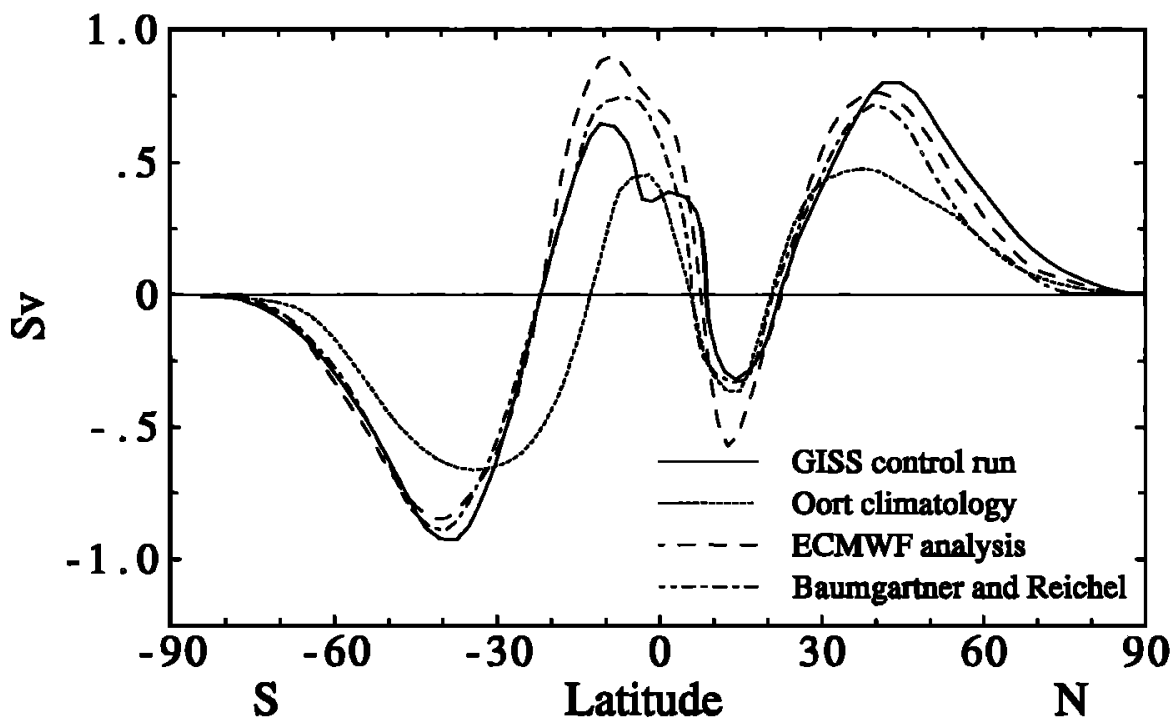

Figure 3. Zonally averaged, vertically integrated meridional water vapor transport for the climatology (dotted line), ECMWF analysis (dashed line) and the AGCM run (solid line). For comparison, data from [Baumgartner and Reichel, 1975] are included (dot-dashed line). Positive values are northward transport.

logy and the the European Center for Medium-Range Weather Forecast (ECMWF) analysis is fairly good in the northern hemisphere. In the southern hemisphere, however, the two data sets differ by up to $50 \%$. Overall the climatology has lower transports than the analysis. In the midlatitudes and high latitudes of the northern hemisphere the agreement with the GISS model stays within the uncertainties of the estimates, with the exception of the polar regions. In the tropics the GISS model overestimates the transport by more than $100 \%$, due to its too high winds in these latitudes.

The zonally averaged and vertically integrated meridional water vapor fluxes $\left(\tilde{Q}^{\phi}\right)$ are shown in Figure 3. In midlatitudes the mean flow is poleward, whereas the lower branches of the Hadley cells transport subtropical moisture into the ITCZ. The AGCM and ECMWF analysis agree well except in the tropical areas of the southern hemisphere. The climatology has in general up to $50 \%$ lower transports over almost all latitudes. In addition, an estimate of the meridional water vapor transport derived from an atlas of evaporation $E$, precipitation $P$, and runoff $R$ is shown [Baumgartner and Reichel, 1975]. It disagrees fairly strongly with Oort's estimates, but is generally in good agreement with the ECMWF analysis.

For a more quantitative comparison of the different data sets we produced point-to-point scatter plots of the various data sets versus one another and calculated their correlation coefficients (Table 1). Although there is no "direct" physical connection between the data sets, one still would expect a significant correlation, as they all should resemble the same planetary processes. The calculated correlation coefficients for the zonal fluxes are around 0.9. This confirms that the zonal circulation patterns are very similar for the various data sets. The mean slopes of the regressions show a fairly good agreement $( \pm 10 \%)$ of the overall strength of the water vapor fluxes between the ECMWF analysis and the GISS AGCM, whereas the fluxes calculated from Oort's climatology are 25-35\% lower (As both data sets in each regression have associated errors, the slope of the regression was calculated as the mean of the slopes that results from treating one data set as a function of the other and vice versa.). The correlation coefficients for the meridional fluxes $\left(\hat{Q}^{\phi}\right)$ are much lower than for the zonal fluxes (about 0.6) indicating again that the zonal

Table 1. Correlation Coefficients and Mean Slopes of the Point-to-Point Comparison of the Yearly Averaged Column Water Vapor Transport and Convergence From the Different Data Sets

\begin{tabular}{lcccccc}
\hline & \multicolumn{2}{c}{ ECMWF-Oort $[1983]$} & & \multicolumn{2}{c}{ GISS-Oort [1983] } \\
\cline { 2 - 5 } & $\begin{array}{l}\text { Correlation } \\
\text { Coefficient }\end{array}$ & $\begin{array}{c}\text { Mean } \\
\text { Slope }\end{array}$ & $\begin{array}{c}\text { Correlation } \\
\text { Coefficient }\end{array}$ & $\begin{array}{c}\text { Mean } \\
\text { Slope }\end{array}$ & $\begin{array}{c}\text { GISS-ECMWF } \\
\text { Correlation } \\
\text { Coefficient }\end{array}$ & $\begin{array}{c}\text { Mean } \\
\text { Slope }\end{array}$ \\
\hline Zonal transport & 0.92 & 1.37 & 0.91 & 1.50 & 0.88 & 1.11 \\
Meridional transport & 0.66 & 1.88 & 0.59 & 1.61 & 0.59 & 0.93 \\
Convergence & 0.35 & 1.61 & 0.24 & 1.99 & 0.61 & 1.01 \\
\hline
\end{tabular}


circulation patterns agree much better between the data sets than do the meridional patterns which generally vary more in space. Again, the magnitude of the fluxes is similar between the analysis and the AGCM but is about $40-50 \%$ lower in Oort's climatology.

\subsection{Atmosphere-to-Ocean Fluxes}

From the convergence of the atmospheric column water vapor fluxes as defined in (2), the atmosphere-toocean freshwater fluxes can be calculated. Under the assumption of steady state (no change of moisture storage in any given volume of air) the water vapor fluxes into grid column $(i, j)$ are balanced by evaporation minus precipitation through the bottom surface $A_{i j}$ :

$$
\rho_{\mathrm{w}} A_{i j}\left(E_{i j}-P_{i j}\right)=\hat{Q}_{i+1, j}^{\lambda}-\hat{Q}_{i j}^{\lambda}+\hat{Q}_{i, j+1}^{\phi}-\hat{Q}_{i j}^{\phi} .
$$

Evaporation and precipitation àre taken in units of meters per second, $\rho_{\mathrm{w}}=10^{3} \mathrm{~kg} / \mathrm{m}^{3}$ is the density of water.

Details of the two-dimensional structure of these fields were presented by Zaucker [1992]. All data sets capture the large-scale features of excess evaporation (divergence) in the subtropics and the excess precipitation (convergence) in the ITCZ and the midlatitudes and high latitudes. However, especially over ocean regions where data are sparse, the climatological estimates are in strong disagreement with the AGCM and ECMWF analysis results, the latter having much more zonal structure.

The point-to-point regression analyses of the convergence fields are presented in Figure 4. As these fields represent the residual of two quantities of comparable magnitude ( $E$ and $P$ ), it is not surprising that the scatter is much larger than for the fluxes and that the correlation coefficients are much smaller. The best agreement is found between the analysis data from ECMWF and the GISS AGCM run, which not only have the highest correlation coefficient $(0.61)$ but also exhibit the same overall magnitude (a linear fit yields a mean slope of 1.0). The climatology is about $40-50 \%$ lower in magnitude than ECMWF or the AGCM and has very low correlation ( 0.35 and 0.24$)$ with these data sets.
To obtain forcing fields for the ocean model, in the following section we construct from the two-dimensional convergence fields the zonally integrated atmosphere-toocean freshwater fluxes $(P-E)$ for the three sectors of the ocean model (Atlantic, Pacific, and Indian Ocean basins, Figure 5). The zonal integration was done over the entire width of the basin as defined by the drainage divide presented in Zaucker and Broecker [1992] and thus includes the corresponding land area. Therefore runoff is implicitly accounted for, although not necessarily at the appropriate latitude. As the major river systems run more or less zonally (the largest river system running in meridional direction is the Mississippi, which carries only about $0.02 \mathrm{~Sv}$ ), this does not introduce a large error in most areas. Such an error could be of some significance for our research, especially in high northern latitudes where Siberian and Canadian rivers are draining into the Arctic Ocean. As the northernmost box in the Atlantic Ocean of the model extends from $65^{\circ} \mathrm{N}$ to $80^{\circ} \mathrm{N}$ this is of little concern for this particular study. Again, even in the zonally integrated fields there is not much resemblance between the three data sets. The figure also shows the implied freshwater flux diagnosed from the control of a twodimensional ocean model described in the next section. A net freshwater loss is diagnosed from the regions of deepwater formation in the Southern Ocean and the northern North Atlantic, whereas all three atmospheric data sets show freshwater input to the surface ocean. The consequences of this discrepancy will be discussed below.

Starting at the North Pole we integrated the zonally averaged $P-E$ fields over the Atlantic drainage basin to obtain the implied oceanic freshwater flux that balances the meridional atmospheric flux (see Figure 6). For comparison, the meridional freshwater flux for the ocean model control run is also included in the figure (discussed below). The three data sets exhibit a similar general structure, with pronounced maxima of freshwater transport toward the equator in the midlatitudes of both hemispheres and with a somewhat smaller poleward transport near the equator. These fluxes can now
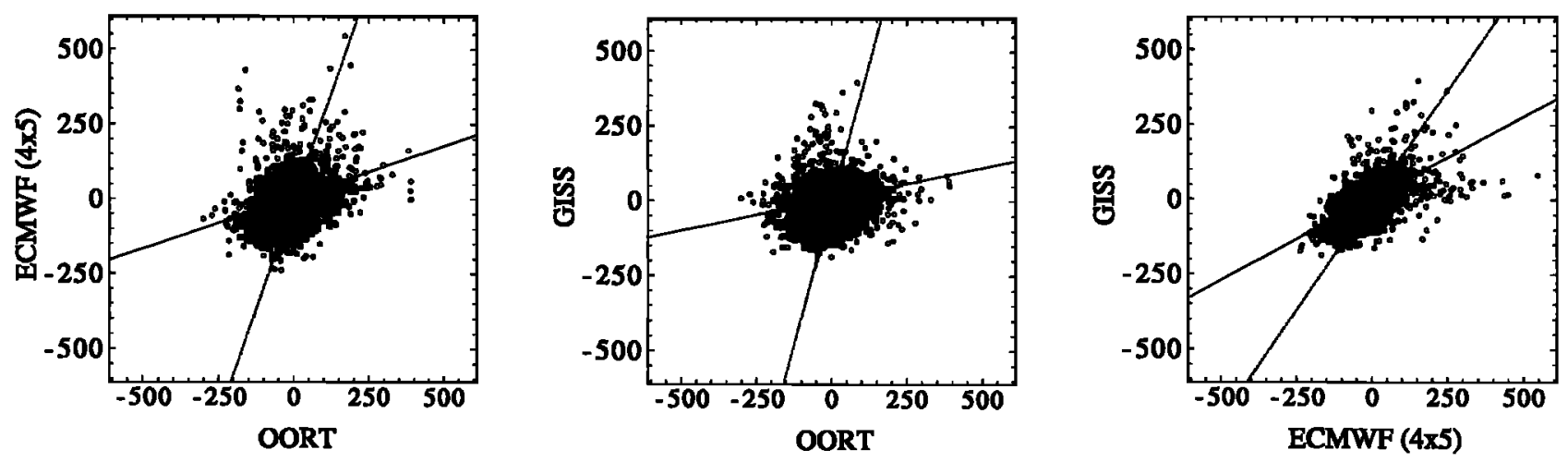

Figure 4. Correlation of water vapor convergence, yearly average for the different data sets, in centimeters per year. For the linear fits the solid line represents $y=f(x)=a x+b$, the dashed line represents $x=f(y)=\tilde{a} y+\tilde{b}$. Correlation coefficients and mean slopes are given in Table 1. 

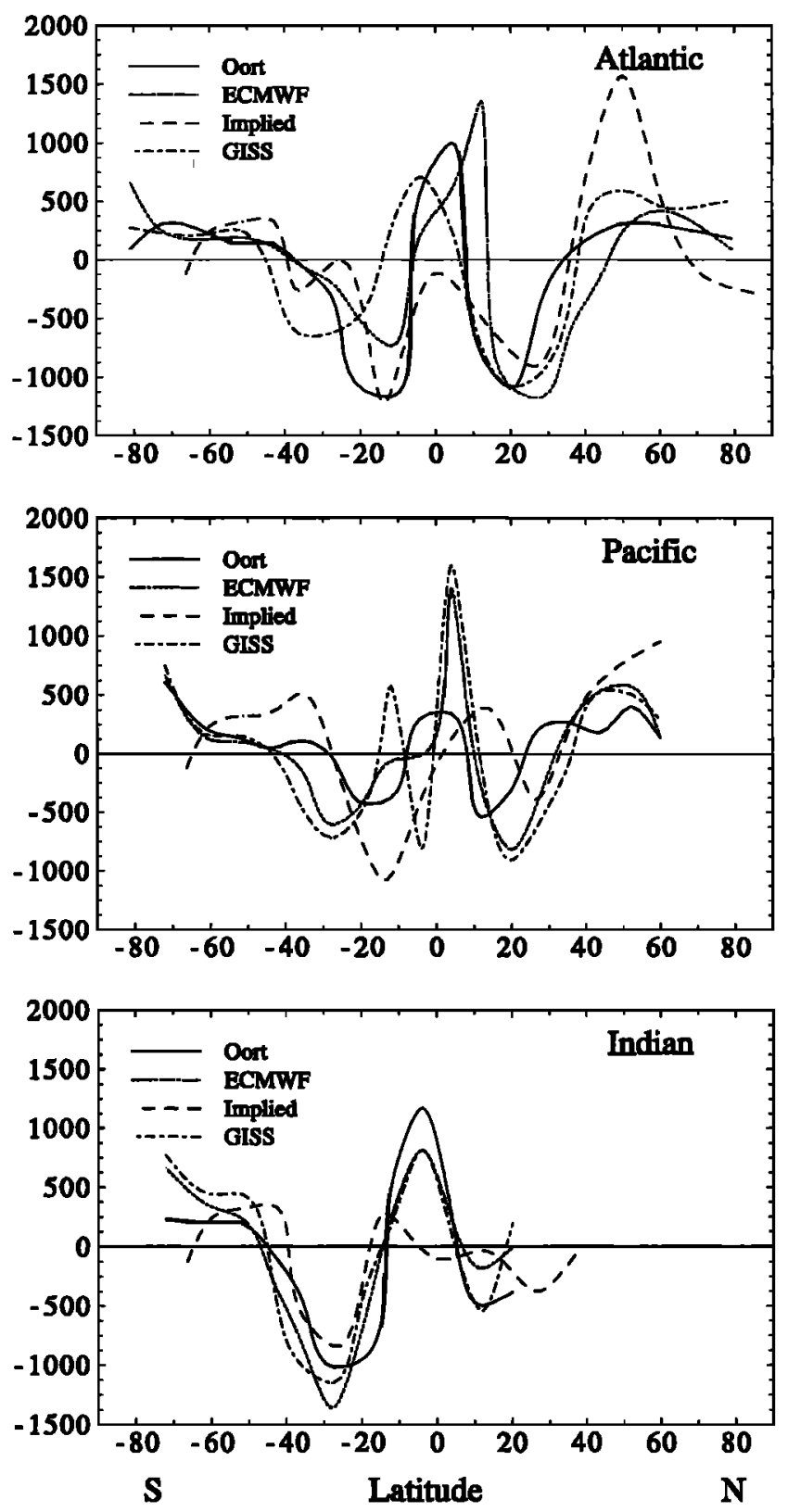

Figure 5. $P-E$ for the Atlantic, Pacific, and Indian Oceans (from top) based on the zonally integrated convergence of atmospheric water vapor from the different data sets and the geometry of the ocean model. The "implied" curve (dashed line) is the diagnosed flux from the control run of the ocean model; all curves are splines through the gridded data; positive values are freshwater flux from the atmosphere to the ocean in mm per year.

be compared to the fluxes given by Schmitt et al. [1992] (hereafter referred to as SBD) that are derived from oceanographic observations (solid line in the figure). The atmospheric data sets (Oort [1983] and ECMWF) agree very well with SBD in the midlatitudes and high latitudes of the northern hemisphere and also in the position of the poleward maximum at around $10^{\circ} \mathrm{N}$. However, the strength of the northward transport at this latitude given by SBD is more than twice that given by
Oort with the ECMWF flux in between. SBD give no significant southward maximum, but rather a minimum of northward transport. ECMWF and Oort agree fairly well in the magnitude of the poleward transport south of the equator, but position the maxima about $10^{\circ}$ apart. In the midlatitudes of the southern hemisphere Oort's data set implies a maximum of equatorward transport about twice as high as ECMWF, and SBD's maximum is at least twice as high as Oort's (SBD's estimate ends at about $30^{\circ} \mathrm{S}$ ). Owing to the high freshwater input to the Arctic Ocean in the GISS model the implied oceanic freshwater fluxes are generally shifted toward southward transport, thus resulting in the strongest equatorward transports in midlatitudes, the lowest poleward transport at $10^{\circ} \mathrm{N}$, and the strongest poleward transport south of the equator.

Figures 5 and 6 show two important features with respect to the freshwater balance of the Atlantic Ocean: (1) the GISS model has a much stronger input of freshwater into the Arctic Ocean and thus a much stronger southward flux of freshwater north of $40^{\circ} \mathrm{N}$ in the Atlantic than any other data set; and (2) the export of freshwater from the Atlantic basin (at about $36^{\circ} \mathrm{S}$ ) is lower in the GISS model than in the two other data sets. The consequences for the thermohaline ocean circulation will be discussed in the following section.

\section{Ocean Model Runs}

The ocean model used in this study was described in detail by Wright and Stocker $[1991 ; 1992]$. It is a twodimensional, latitude-depth model which solves zonally averaged balance equations of mass, momentum, temperature, and salt. Time dependence is only retained in the latter two balances, and hence the circulation is diagnosed from the zonally averaged density distribution. Instabilities are removed by convective mixing. The model geometry consists of three basins representing the Pacific, Atlantic, and Indian Oceans which are connected by the Southern Ocean (Figure 7). The circulation is driven by momentum and buoyancy fluxes through the surface, and a zonally averaged zonal surface wind stress as given by Han and Lee [1983] is specified. In order to obtain a steady state, surface temperature $T$ and salinity $S$ of the model are relaxed to observations according to

$$
\begin{aligned}
& F_{H}=\frac{H_{\mathrm{m}}}{\tau_{H}}\left(T-T^{\star}\right), \\
& F_{S}=\frac{H_{\mathrm{m}}}{\tau_{S}}\left(S-S^{\star}\right),
\end{aligned}
$$

where $F_{H}$ and $F_{S}$ are the implied heat and salt fluxes, respectively, $H_{\mathrm{m}}$ is the mixed layer depth, $\tau_{H}$ and $\tau_{S}$ are restoring timescales, $T$ and $S$ are temperature and salinity of the model surface layer, and $T^{\star}$ and $S^{\star}$ are prescribed values of temperature and salinity taken from Levitus [1982]. Equations (5a) and (5b) describe the restoring boundary conditions that are frequently used in ocean only models. For studies relevant to climate 


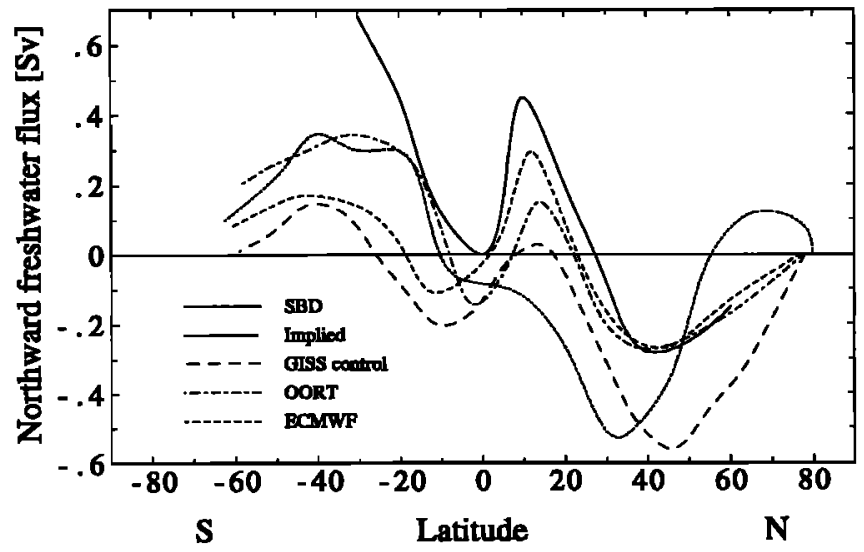

Figure 6. Implied meridional oceanic freshwater transport in the Atlantic Ocean (zonal average) derived from the zonally averaged $P-E$ field over the drainage basin for the various data sets. The solid curve is an estimate adapted from Schmitt et al. [1992] based on oceanographic observations. The "implied" curve is the flux diagnosed from the control run of the ocean model; all lines are splines through the gridded data; positive values are northward flux in sverdrups.

change, mixed boundary conditions are preferred; i.e., $F_{S}$ is held fixed while $F_{H}$ is calculated according to (5a). This is a better approximation because of the absence of a local feedback between sea surface salinity anomalies and the surface freshwater balance that would be implied by (5b).

In this section we investigate which of the atmosphere-to-ocean freshwater fluxes presented in the previous section are consistent with the observed thermohaline ocean circulation. The two-dimensional ocean model is first run with restoring boundary conditions at the sea surface for both temperature and salinity (from Levitus [1982], modified in the Southern Ocean (see section 3.1)). The diagnosed or implied freshwa- ter flux, (5b), from this run is then used to force the model under mixed boundary conditions, i.e., restoring of temperature and specified freshwater flux. This control run serves as a reference for experiments where the freshwater fluxes from the climatology, ECMWF analysis, and AGCM run are applied as boundary conditions for the ocean model. The sensitivity of NADW and Antarctic Bottom Water (AABW) formation and the strength of the meridional overturning to modifications in the surface freshwater fluxes will then be examined. Finally, we will examine the stability of our results when key model parameters are varied. The various runs are listed in Table 2.

\subsection{Control Run}

Zonally averaged values of temperature and salinity at $30 \mathrm{~m}$ as given by Levitus [1982] are used to run the model under restoring boundary conditions (experiment 1). Stocker et al. [1992] showed, that relaxation of salinity to the observed surface salinity in the Southern Ocean (zonally averaged, annual mean about $34 \%$ [Levitus, 1982]) does not produce AABW in their model. They argue that the observations are summer biased due to the logistical difficulties of polar winter expeditions. Therefure for this control run the southernmost boxes were relaxed to the salinity typically observed in newly formed AABW (34.6\%). A mixed layer depth $H_{\mathrm{m}}=50 \mathrm{~m}$ is specified with the restoring timescales $\tau_{H}=\tau_{S}=50$ days.

Figures 8 and 9 show latitude-depth plots of the meridional stream function, temperature, and salinity structure of the Atlantic and Pacific Oceans. The meridional overturning stream function representing conservation of mass is defined by

$$
v=-\frac{1}{H c} \frac{\partial \psi}{\partial z}, \quad w=\frac{1}{a} \frac{\partial \psi}{\partial s}
$$

with the meridional and vertical velocities $v$ and $w$, re-

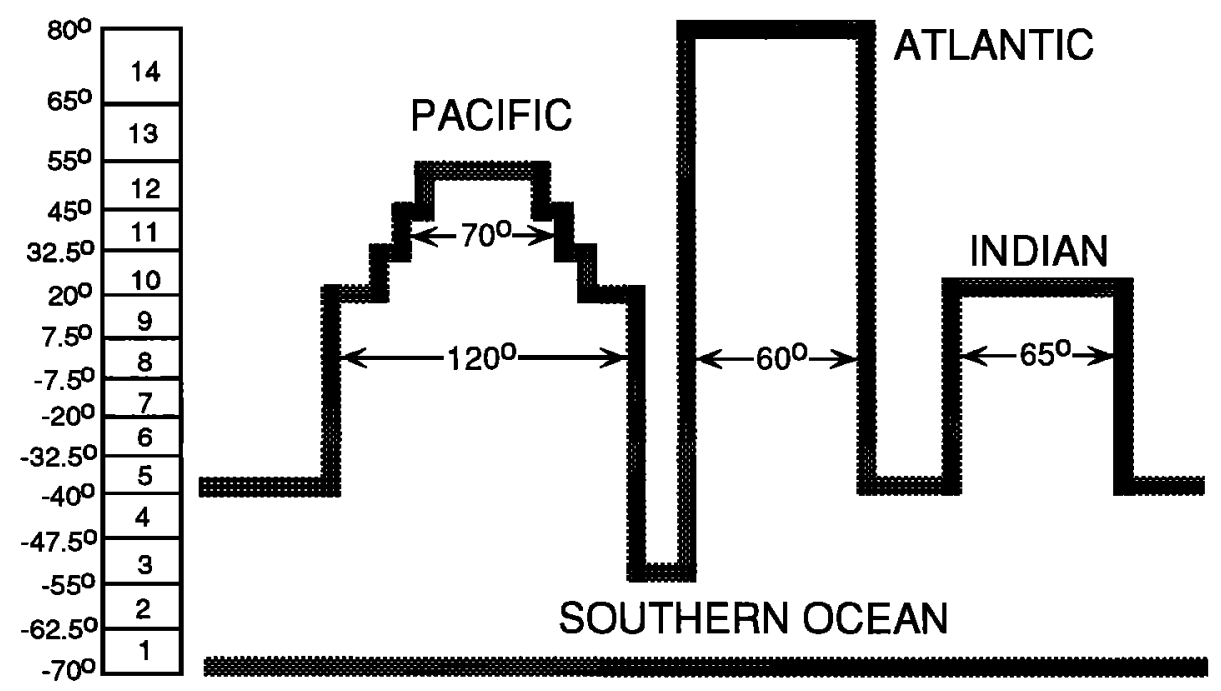

Figure 7. Idealized model representation of the global ocean. The Pacific, Atlantic, and Indian Ocean basins are connected by the Southern Ocean basin. The model has a flat bottom. 
Table 2. Summary of the Model Runs Discussed in This Paper

\begin{tabular}{|c|c|c|c|}
\hline Exp. & Description & Circulation & Figure \\
\hline 1 & $\begin{array}{l}\text { control run; restoring } T \text { and } S \text { to Levitus' } 1982 \\
\text { climatology }\end{array}$ & NADW, AABW (modern) & 8,9 \\
\hline 2 & $\begin{array}{l}\text { mixed boundary conditions (MBC) with diag- } \\
\text { nosed freshwater flux from experiment } 1\end{array}$ & (modern) & - \\
\hline 3 & freshwater flux from Oort [1983] & NADW, no AABW & 10 \\
\hline 4 & freshwater flux from ECMWF & NADW, no AABW & 11 \\
\hline 5 & freshwater flux from GISS AGCM & southern sinking & 12 \\
\hline 6 & $\begin{array}{l}\text { freshwater flux from Oort [1983] modified to } \\
\text { reestablish AABW formation }\end{array}$ & modern & - \\
\hline 7 & $\begin{array}{l}\text { freshwater flux from ECMWF modified to reestab- } \\
\text { lish AABW formation }\end{array}$ & modern & - \\
\hline 8 & $\begin{array}{l}\text { freshwater flux from GISS modified to reestablish } \\
\text { NADW and AABW formation }\end{array}$ & modern & - \\
\hline 9 & $\begin{array}{l}\text { like experiments } 1,3,4 \text {, and } 5 \text {, but with the } \\
\text { vertical diffusion coefficient varied from } 0.5 \text { to } \\
2 \times 10^{-4} \mathrm{~m}^{2} \mathrm{~s}^{-1}\end{array}$ & as in $1,3,4,5$ & - \\
\hline 10 & $\begin{array}{l}\text { like experiments } 3 \text { and } 4 \text {, but started from various } \\
\text { initial conditions, e.g., ocean at rest (see text) }\end{array}$ & southern sinking & - \\
\hline 11 & $\begin{array}{l}\text { like experiment } 6 \text {, but atmospheric freshwater ex- } \\
\text { port from the Atlantic basin varied from } 0 \text { to } 1 \mathrm{~Sv}\end{array}$ & increasing NADW & 13,14 \\
\hline 12 & $\begin{array}{l}\text { like experiments } 3 \text { and } 4 \text {, but with a parameterized } \\
\text { freshwater flux through Bering Strait of } 0.05 \text { to } \\
0.2 \mathrm{~Sv}\end{array}$ & NADW shutdown above $0.15 \mathrm{~Sv}$ & - \\
\hline
\end{tabular}

All runs except 1 and 2 are forced with mixed boundary conditions, i.e., $T$ restored to Levitus' [1982] climatology and the freshwater flux as given.

spectively, $s=\sin \phi, c=\cos \phi$, longitude $\phi$, depth $z$, ocean depth $H$, and $a$ the radius of the earth. Thus $\psi$ has the dimensions of a volume transport $\left(\mathrm{m}^{3} \mathrm{~s}^{-1}\right)$. A comparison to cross sections of the zonal averages of the observed temperature and salinity [Levitus, 1982] shows that the model simulates the main features fairly realistically. In the subtropics of the northern and southern Atlantic and Pacific Oceans, high-salinity pools are present at and below the surface. These are related to the excess of evaporation over precipitation in these lat- itudes. The position of these maxima is slightly shifted to higher latitudes in the model compared to the observations. At about $10^{\circ} \mathrm{N}$ we find low-salinity waters associated with the ITCZ. Deepwater formation occurs in the high latitudes of the Atlantic (north of $65^{\circ} \mathrm{N}$ ). NADW which is characterized by salinities above $34.9 \%$ and relatively low temperature, flows southward below $1000 \mathrm{~m}$ depth, with the core at around $3000 \mathrm{~m}$. Below the NADW core and south of the equator we find AABW which is slightly higher in salinity than
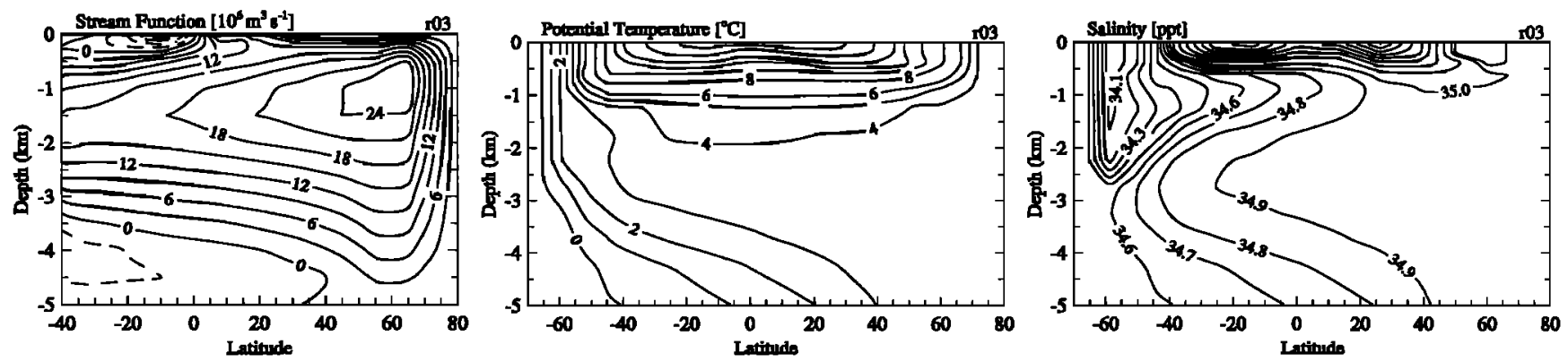

Figure 8. Meridional stream function (in sverdrups), potential temperature (in degrees Celsius), and salinity (per mil) of the model control run (restoring boundary conditions to surface salinity and temperature from Levitus [1982]) for the Atlantic basin. The clockwise meridional overturning of the thermohaline circulation is shown by the positive values of the stream function (solid lines); the high-salinity NADW ( $>34.9 \%$ ) has its core at about $3000 \mathrm{~m}$ depth; the counterclockwise cell of AABW can be seen in the deep southern part of the basin (dashed line); relatively low-salinity AAIW overlies NADW. 

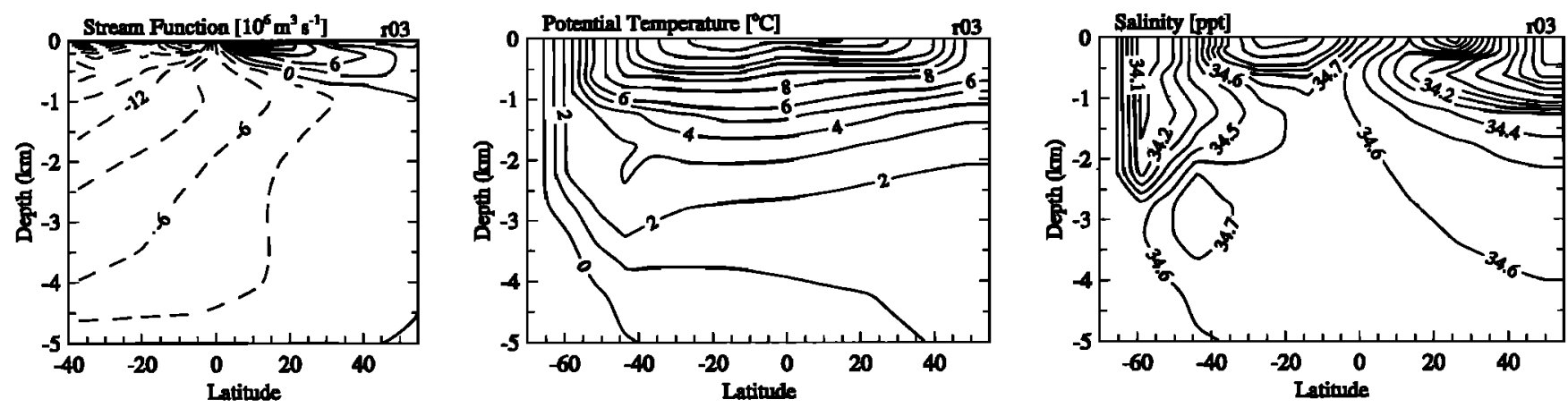

Figure 9. Same as Figure 8, but for the Pacific basin. Only intermediate water and no deepwater is formed in the North Pacific; circulation is characterized by northward flow in the deep ocean and large-scale upwelling; AAIW and AABW are present in the southern part of the basin.

Antarctic Intermediate Water (AAIW), but still is a relative salinity minimum (lowest in the Atlantic basin). AABW is the coldest water in the deep ocean and owing to its high density underlies NADW. In the southern ocean starting at the surface and $70^{\circ} \mathrm{S}$ to $60^{\circ} \mathrm{S}$, the lowsalinity tongue of AAIW extends first northward and downward to a depth of about $1000 \mathrm{~m}$ to $1500 \mathrm{~m}$ and then slopes upward again into the tropical ocean. The temperature of this water mass is relatively low, but owing to its smaller salinity it is less dense than the underlying NADW. In both ocean basins this feature extends farther down in the model than in the observations. Both AAIW and AABW are present in the southern part of the basins. The high sea surface temperature (SST) in the Indian Ocean (not shown) and the relatively low sea surface salinity (SSS) in the North Pacific prevent deepwater formation, and only intermediate waters are formed. The overall deep circulation is northward and characterized by large-scale upwelling. Because of the simplified dynamics and the fairly coarse resolution, the model does not capture many of the details seen in the observations. Features related to bottom topography and the southern or the northern polar oceans are not resolved by the model, and the highsalinity inflow from the Mediterranean and Red Seas are not included. The effect of these marginal seas is minor in this ocean model. For a further discussion of the model performance see Wright and Stocker [1992].

From the equilibrium state of the run under restoring boundary conditions the implied freshwater fluxes were diagnosed according to $(5 \mathrm{~b}$ ) (see Figure 5 and the discussion in the previous section). The model was then switched to mixed boundary conditions with relaxation of SST and freshwater flux from the spin-up (experiment 2). The same circulation was achieved as in the spin-up run. We should mention here that the choice of 50 days as the relaxation time is somewhat arbitrary, especially for salinity, because of the nonexisting local feedback between sea surface salinity (SSS) and the $P-E$ field. Thus we repeated the spin-up runs for relaxation times from $\tau_{S}=50,100,200$, and 365 days. The magnitude of the diagnosed atmosphere-to-ocean freshwater flux does indeed vary somewhat in response to this parameter (larger amplitudes with shorter re- laxation time). However, the general structure of the field remains the same. The results and conclusions presented here are insensitive to these variations over the range of relaxation times investigated.

As the emphasis of this study is on NADW formation and the meridional overturning in the Atlantic, we will only present figures for the Atlantic Ocean in the remainder of this paper. Throughout the experiments shown here the changes in the circulation within the Pacific and Indian Oceans were minor.

\subsection{Forcing With Atmospheric Freshwater Fluxes}

The atmosphere-to-ocean freshwater fluxes derived from Oort's [1983] climatology (experiment 3) and from the ECMWF analysis (experiment 4) were used as salt flux boundary conditions for the ocean model. The resulting stream function and temperature and salt distribution in the Atlantic basin are shown in Figures 10 and 11. Both surface fluxes are consistent with NADW formation. However, no AABW is formed in either of the two runs thus leaving the deep ocean too warm and too salty in the south. The resulting meridional overturning is stronger than in the control run $(25 \mathrm{~Sv})$ by about $15 \%$ in the run forced with the climatological fluxes ( $30 \mathrm{~Sv}$ ) and by about $30 \%$ if forced with ECMWF freshwater fluxes (33 Sv). At least part of the increased strength of the meridional stream function can be attributed to the absence of the deep inflow of AABW (see below). This was also observed by Yin et al. [1992]. Although the freshwater export from the Atlantic drainage basin is only about half as large in the analysis as in the climatology, the overturning is still stronger, probably because of stronger NADW formation due to less freshwater input to the Arctic Ocean.

The most dramatic change relative to the control run occurs when the ocean model is forced with the freshwater fluxes as simulated with the GISS AGCM (experiment 5). The strong freshwater input to the Northern Polar Ocean (Figure 5) of $0.26 \mathrm{~Sv}$ freshens the surface waters to such an extent that NADW formation is shut down and so results in a reversed meridional circulation with "southern sinking" around Antarctica and up- 

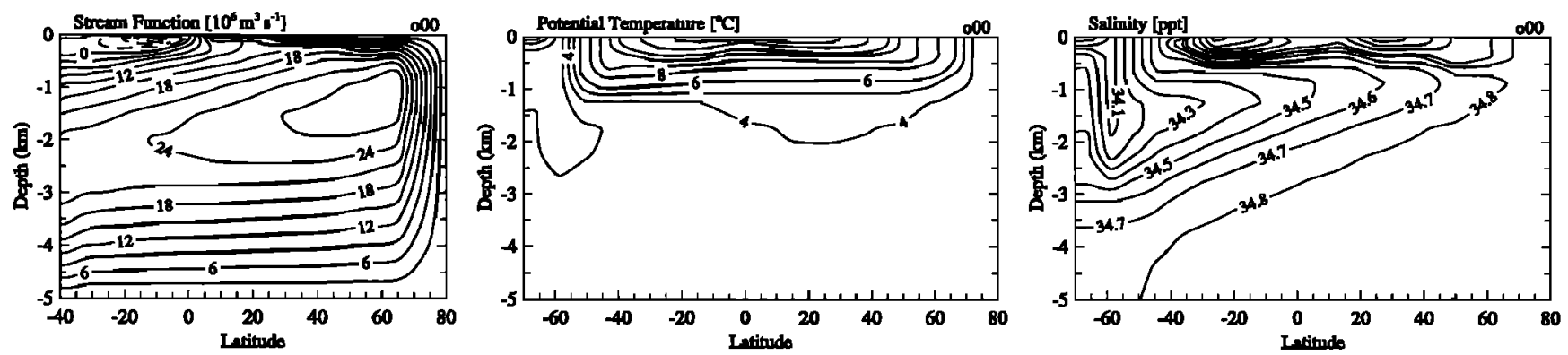

Figure 10. Meridional stream function (in sverdrups), potential temperature (degrees Celsius), and salinity (per mil) of the model forced with freshwater fluxes from Oort [1983]; the thermohaline circulation is operational but stronger than in the control run; no AABW is formed and thus NADW extends all the way to the bottom of the ocean.

welling in the North Atlantic (Figure 12). To date there is no evidence from observations that this mode of the ocean circulation ever existed in the near past, although it is a possible solution in many ocean models [Marotzke and Willebrand, 1991; Stocker and Wright, 1991; Stocker et al., 1992]. It should be noted that although the GISS AGCM has the strongest freshwater input to the Arctic Ocean of all three atmospheric data sets, it is only slightly higher than the freshening derived from the ECMWF analysis. Nevertheless, this slight increase is sufficient to shut down NADW formation. This might be connected to the net freshwater export from the Atlantic basin (see below), which is somewhat lower in the GISS AGCM than in the ECMWF analysis. However, freshwater input to the northern North Atlantic is also very high and might precondition the northward currents, rendering the Atlantic circulation much less stable.

\section{Sensitivity Experiments}

Several model runs have been performed to investigate the sensitivity of the deepwater formation and the meridional overturning rate in the ocean model. For this purpose the atmosphere-to-ocean freshwater fluxes were arbitrarily changed at certain latitudes. To maintain a global freshwater balance, opposite changes were imposed at a location that was considered relatively unimportant to the problem. This allows the establishment of the degree of incompatibility of the atmo- spheric freshwater fluxes and the ocean model's inability to maintain deepwater formation in both southern and northern latitudes.

\subsection{Maintenance of the Modern Circulation}

In two experiments using the atmosphere-to-ocean fluxes from Oort [1983] and ECMWF, the freshwater input to the southernmost ocean box was continuously decreased until AABW formation similar to the control run was reestablished. This high-latitude change was balanced by an area-weighted increase in freshwater input over the global ocean. For the run with Oort's [1983] boundary condition (experiment 6) the flux to the Southern Ocean had to be changed from $+0.03 \mathrm{~Sv}$ to $-0.2 \mathrm{~Sv}$, whereas for ECMWF boundary conditions (experiment 7 ) a change from $+0.21 \mathrm{~Sv}$ to $-0.15 \mathrm{~Sv}$ was required.

A more serious incompatibility with the modern ocean circulation was found when applying the freshwater fluxes from the GISS AGCM. Rather than only changing the water mass distribution in the deep ocean, excess precipitation in the northern North Atlantic triggers a polar halocline catastrophe, and the deep circulation in the Atlantic reverses. To determine the amount of additional evaporation needed, we used the boundary conditions derived from the GISS AGCM and modified them in the northernmost box of the Atlantic Ocean until NADW formation was reinitiated. The freshwater input to the Arctic Ocean had to be decreased from $+0.26 \mathrm{~Sv}$ in the control run to $+0.18 \mathrm{~Sv}$. An additional
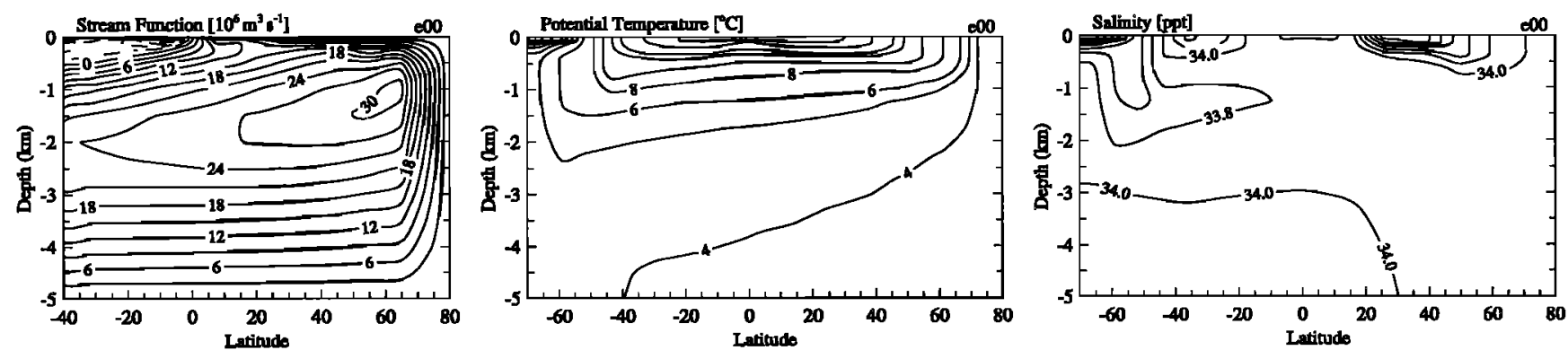

Figure 11. Meridional stream function (in sverdrups), potential temperature (degrees Celsius), and salinity (per mil) of the model forced with freshwater fluxes from ECMWF analysis; the meridional overturning is too strong and no AABW is formed; NADW extends to the bottom. 

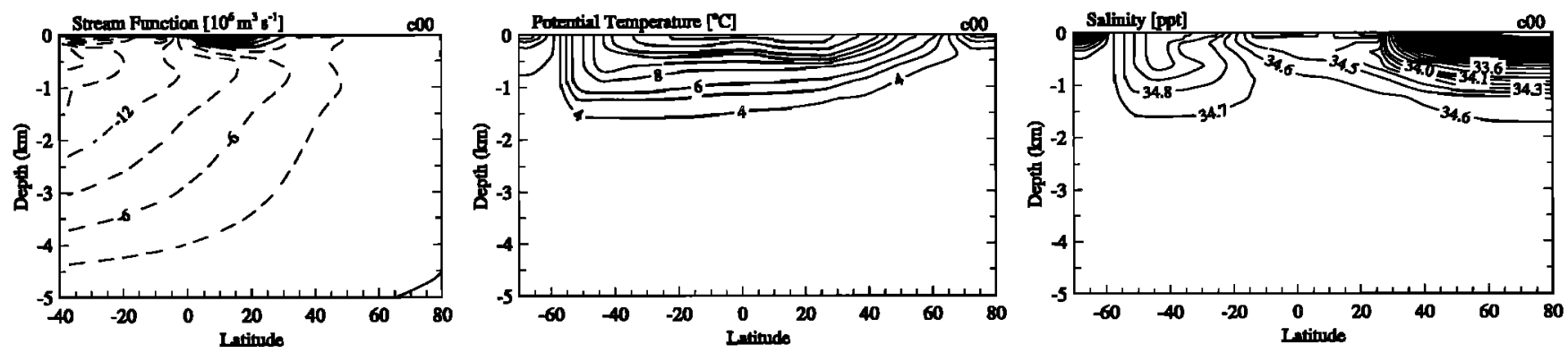

Figure 12. Meridional stream function (in sverdrups), potential temperature (degrees Celsius), and salinity (per mil) of the model forced with freshwater fluxes from the GISS AGCM; the strong freshwater input to Arctic Ocean leads to a strong stratification and no NADW formation occurs; the circulation is characterized by southern sinking and upwelling in the Atlantic Ocean. Note the strong polar halocline in the North Atlantic.

adjustment of the flux to the Southern Ocean from $+0.09 \mathrm{~Sv}$ to $-0.1 \mathrm{~Sv}$ was necessary to establish AABW formation. Decreasing the northern polar ocean flux further to $+0.15 \mathrm{~Sv}$ achieved a circulation similar to the control run, although with a somewhat weaker thermohaline circulation (experiment 8).

\subsection{Influence of Vertical Diffusivity}

Wright and Stocker [1992] have shown that the model circulation is sensitive to the value of the vertical diffusion coefficient $K_{\mathrm{v}}$. The value for the control run was $1 \times 10^{-4} \mathrm{~m}^{2} \mathrm{~s}^{-1}$. To ensure that the results and conclusions from the experiments described above are robust features and not artifacts of an unfortunate choice of $K_{\mathrm{v}}$, we repeated experiments $1,3,4$, and 5 with $K_{\mathrm{v}}=0.5 \times 10^{-4} \mathrm{~m}^{2} \mathrm{~s}^{-1}$ and $K_{\mathrm{v}}=2 \times 10^{-4} \mathrm{~m}^{2} \mathrm{~s}^{-1}$.

Generally, deepwater formation and meridional overturning increased with increasing $K_{\mathrm{v}}$, but the overall circulation pattern was not changed. Gradients in the latitude-depth distribution of salinity and temperature were somewhat smoothed out in response to the stronger vertical mixing with increasing $K_{\mathrm{v}}$, and essentially the opposite holds for decreasing $K_{\mathrm{v}}$. The run with restoring boundary conditions for both salinity and temperature for $K_{\mathrm{v}}=0.5 \times 10^{-4} \mathrm{~m}^{2} \mathrm{~s}^{-1}$ yielded a meridional overturning of about $21 \mathrm{~Sv}$, which is probably closer to reality than the control run of experiment 1 .

The conclusions reached in the experiments above therefore do not depend critically on the value chosen for $K_{\mathrm{v}}$, although the absolute values of the necessary adjustments to the surface fluxes would vary slightly.

\subsection{Multiple Equilibria}

After spin-up of the model under restoring boundary conditions for both temperature and salinity, all further experiments were run under mixed boundary conditions with $P-E$ fields from various sources. Several authors have shown before that multiple equilibria exist under mixed boundary conditions. This is also the case for our model. Several runs with freshwater forcing derived from ECMWF and Oort's [1983] work have been made with different initial conditions to verify this behavior. When the model was spun-up from an ocean at rest (uniform temperature and salinity dis- tribution), the model immediately went into the mode with southern sinking in all three basins and equilibrium was reached within a few centuries. When the model was spunup from an initial state that favored sinking in the North Atlantic (ocean at rest but with a temperature minimum of $5^{\circ} \mathrm{C}$ either north of the equator or in the northernmost box), a strong overturning cell in the North Atlantic developed. However, this cell did not extend southward of the equator and diminished quickly since not enough high-salinity water was transported into the source region of NADW and also because of the counteracting influence of the developing reversed cell in the South Atlantic. After less than 50 years NADW formation ceased and the model approached the southern sinking mode (equilibrium reached again after a few hundred years).

We conclude that at least two stable equilibria exist under mixed boundary conditions with $P-E$ fields from ECMWF and Oort. Only when the initial state of the model was close to a conveyor belt circulation was this state stable under mixed boundary conditions. In contrast, no such solution could be found for freshwater forcing derived from the GISS AGCM.

\subsection{Variation of the Atlantic Freshwater Balance}

The simple picture of the link between the freshwater balance of the Atlantic Ocean and the thermohaline circulation as presented in Figure 1 suggests that the strength of the meridional overturning responds linearly to changes in the net atmospheric export of freshwater from the Atlantic drainage basin. In a set of model runs we artificially changed this balance by modifying the freshwater input to the surface ocean in low latitudes. Starting with the boundary conditions from experiment 6 (modified climatology), freshwater was removed from the tropical Atlantic and added to the tropical Pacific Ocean in amounts ranging from 0 to $1.5 \mathrm{~Sv}$ (the steady state value in experiment 4 was $0.32 \mathrm{~Sv}$ ). The response of the ocean model is shown in Figure 13. NADW formation starts at a freshwater export of about $0.1 \mathrm{~Sv}$, and the strength of the thermohaline circulation increases steadily with increasing freshwater loss from the Atlantic Ocean. The sensitivity to changes in the freshwater flux is highest at low overturning rates. The 


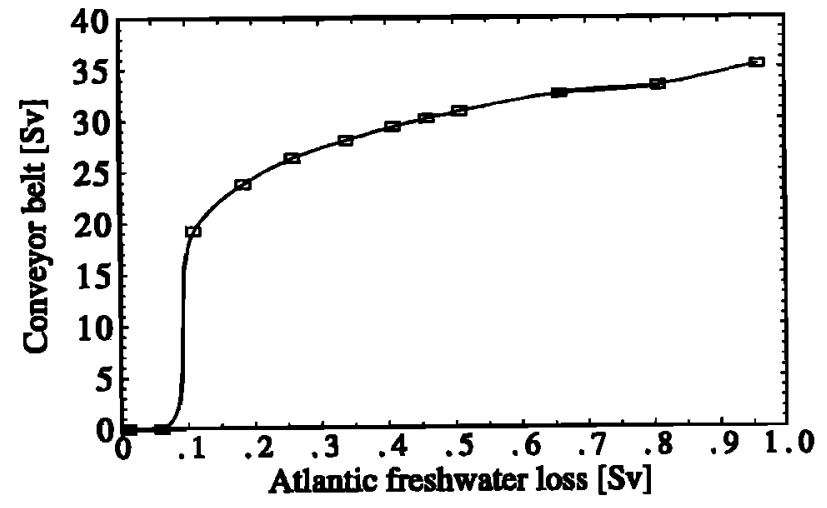

Figure 13. Strength of the thermohaline circulation as a function of the freshwater export from the Atlantic drainage basin.

amplification factor $A$, which was introduced as the ratio of the strength of the conveyor belt $C$ and the atmospheric freshwater export from the Atlantic $E$, decreases almost linearly with the increase in the circulation (Figure 14):

$$
A=\frac{C}{E} \sim \frac{1}{C} .
$$

Solving for $C$ we find

$$
C \sim \sqrt{E}
$$

This demonstrates clearly that the linear view implied in Figure 1 is too simple. The sudden onset of the overturning (around 0.1Sv freshwater export) and the nonlinear behavior of the system is due to a positive feedback loop. Once the conveyor gets started it transports high-salinity water into the region of NADW formation, which in turn increases the density and thus the deepwater formation rate. The exact relationship of (8) or the point of onset of the conveyor belt in Figure 13 might be to some extent model dependent. This will have to be decided after similar experiments with three-dimensional models for example.

Another aspect of the Atlantic freshwater balance is the low-salinity inflow to the Arctic Ocean from the $\mathrm{Pa}$ -

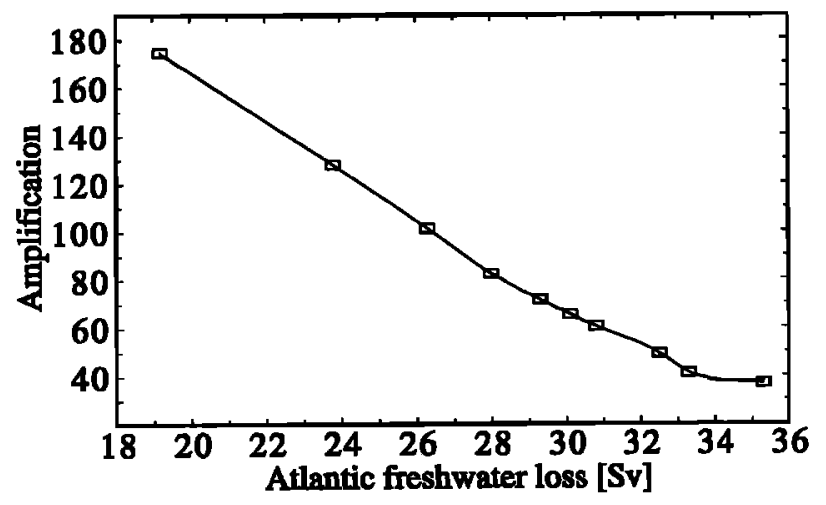

Figure 14. Sensitivity of the amplification factor defined as the ratio between maximum overturning and Atlantic freshwater loss to changes in net freshwater forcing; see also Figure 1 . cific Ocean through the Bering Strait. This inflow is on the order of $0.8 \mathrm{~Sv}$ with a salinity of about $32.5 \%$. The outflow into the Atlantic Ocean has a salinity of about $34.6 \%$. The salinity anomaly of the Bering Strait flow of about $-2 \%$ is thus equivalent to a freshwater flux of about $0.05 \mathrm{~Sv}$. We included a simple parameterization of Bering Strait through flow in our model by removing freshwater from the northernmost surface box of the Pacific Ocean and adding it to the Arctic Ocean surface box. The runs with $P-E$ boundary conditions from ECMWF and Oort [1983] were repeated with this parameterization included. The conveyor belt remained stable for perturbation fluxes of up to $0.15 \mathrm{~Sv}$ ( 3 times the estimated Bering Strait through flow). A further increase to $0.2 \mathrm{~Sv}$ resulted in a transition to southern sinking and upwelling in all three basins. The run with GISS $P-E$ fields yielded no conveyor belt, and the additional freshwater flux to the Arctic Ocean would make this situation more pronounced.

\section{Discussion}

The freshwater surface forcing for all three major ocean basins is very different in the three atmospheric data sets used in this study. They differ both in strength and regional distribution. This is true even for the zonally averaged fields (Figure 5). Both the observed and the modeled atmospheric fluxes are very different from the fluxes that are diagnosed from the control run of the two-dimensional ocean model (restoring boundary conditions to Levitus' [1982] climatology). Despite these differences, both the fluxes based on Oort's [1983] work and ECMWF are able to sustain a global thermohaline circulation similar to that observed and are stable to perturbation by freshwater input to the Arctic Ocean of more than 3 times the amount estimated for Bering Strait through flow.

The net freshwater loss from the Atlantic drainage basin is $0.13 \mathrm{~Sv}$ for the GISS AGCM, $0.18 \mathrm{~Sv}$ for the ECMWF analysis, and $0.32 \mathrm{~Sv}$ according to Oort's climatology. Our experiments have clearly shown that a net freshwater loss from the Atlantic Ocean is necessary but not sufficient to maintain a modern thermohaline overturning. The strong freshwater input to the Arctic Ocean produced by the GISS AGCM decreases the salinity of the mixed layer to the extent that deep water formation is shut down (at low temperatures the density of sea water is much more sensitive to salinity changes than to temperature).

The strength of the overturning in the Atlantic is related to the net freshwater export from the Atlantic drainage basin (Figure 13). The sensitivity to changes in the freshwater balance is greatest near the transition between the on and off mode and decreases almost linearly with increasing meridional overturning. From this ocean model's results, the net freshwater export is clearly the driving mechanism of the conveyor belt. On the other hand, one can argue that the Atlantic Ocean is a net evaporative basin because of the existence of the conveyor belt and the associated SST distribution [e.g., Warren, 1983; Hughes and Weaver, 1993]. It should 
be noted that the strength of the conveyor belt is not solely determined by Atlantic freshwater export and other mechanisms also have to be considered (e.g. wind stress curl [Toggweiler and Samuels, 1993], steric height drop [Hughes and Weaver, 1993], north-south bouancy contrast [Stocker et al., 1992]).

In our study the existence of a stable modern-day circulation with sinking in the North Atlantic and the Southern Ocean and upwelling in the North Pacific depends critically on a net atmospheric freshwater export from the Atlantic drainage basin. On the contrary, Marotzke and Willebrand [1991] and Hughes and Weaver [1993] found equilibrium states of their models with conveyor-beltlike circulations, even with the Atlantic being a weakly precipitative basin. In both studies the ocean model had been forced with idealized boundary conditions for temperature and salinity (symmetric across the equator). In addition, the mode found by Hughes and Weaver was not stable under mixed boundary conditions, leading to strong sinking in the North Pacific and no sinking in the North Atlantic. All other states of Hughes and Weaver's which were spunup under geometrically more realistic (nonsymmetric) boundary conditions exhibit net evaporation over the Atlantic drainage basin and a modern-day thermohaline circulation.

The transition between the "conveyor on" and "conveyor off" mode is very sharp. If operating close to the transition, a change in freshwater input to the Arctic Ocean of $0.01 \mathrm{~Sv}$ is sufficient to shut down deepwater formation. A similar sensitivity of the thermohaline circulation to changes in freshwater forcing in this region has been demonstrated previously in twoand three-dimensional models [e.g., Mikolajewicz and Maier-Reimer, 1990; Stocker and Wright, 1991]. This sensitivity is due to the positive feedback supplying saline waters from low latitudes to the source region of deepwater formation when the overturning is operational [Bryan, 1986]. It is clear that the exact position where this switch occurs might very well be model dependent or even depend on other climatic variables.

AABW formation is also determined by the freshwater input to the source region, but because of the missing feedback mechanism the response to changes in the surface fluxes is much more linear. Unlike in the Atlantic, where a direct path of surface waters exists from the low latitudes where the saline waters are formed by excess evaporation to high latitudes, the Southern Ocean provides a barrier to such a direct connection to the lower latitudes. Surface waters flowing southward and exiting from the three basins are mixed zonally, and hence salinity anomalies coming from the Atlantic are diluted before they can reach the areas where AABW is formed in the model. None of the three data sets is compatible with the fluxes required by the ocean model to maintain realistic AABW. The ocean model requires a fairly strong export of freshwater from this region of the order of $0.15 \mathrm{~Sv}$. While water mass formation is crudely represented in the present model, one should also note that data coverage in this area is poor at best. The atmospheric freshwater input might be much smaller than presented above. It seems unlikely, however, that the atmosphere is able to account for a net export, as the general meridional circulation is transporting moisture from low latitudes toward the poles. This suggests two other mechanisms: (1) freshwater could be exported from the Southern Ocean by advection of sea ice, or (2) seasonal and regional processes like brine release by sea ice formation must be invoked to explain AABW formation.

In the control run for this study the southernmost boxes were relaxed to the salinity typically observed in newly formed AABW (34.6\%) rather than to the SSS given by Levitus [1982] (34.0\%0). This is equivalent to a reduced freshwater input to this area of about $0.013 \mathrm{~Sv}$. The surface flux adjustments to the atmospheric observations in this region $(0.2-0.3 \mathrm{~Sv})$ are more than 10 times higher than the flux change implied by the $0.6 \%$ change in salinity and are of the order of or larger than the net atmospheric transport between the Atlantic and Pacific basins (0.1-0.3Sv). We must conclude that the freshwater input to the Southern Ocean as calculated from the observations is not compatible with this ocean model. As the observational database is poor in this region, it can not be decided if this is a problem of the ocean model or a problem of the atmospheric data.

Thus we have demonstrated that both the existence and the strength of the thermohaline circulation depend critically on the atmospheric freshwater fluxes to the polar oceans and that the thermohaline circulation is fairly insensitive to the latitudinal structure of the forcing in low latitudes. To collect observations of the required accuracy over these large regions in order to verify atmospheric models and improve our understanding of deepwater formation processes is most certainly a big challenge. The discrepancy between atmospheric and oceanic estimates of the $P-E$ fields is an important issue for coupled modeling studies.

Acknowledgments. We thank Adrian Simmons, Norbert Kreitz, and their colleagues for their hospitality during a visit at ECMWF and for providing us with the ECMWF data set. Edward Birchfield suggested the use of ECMWF analysis. NASA/GISS provided computer time and the data from the AGCM runs. Jasmin John and Reto Ruedy helped with running the GCM. Mark Cane, Inez Fung and Daniel Wright helped with numerous discussions. We also thank Andrew Weaver for his extensive and careful review and two further anonymous reviewers for their comments. This research was supported by EPRI grant RP2333-6 and grant DE-FG02-91ER61202 of the U.S. Department of Energy. F. Zaucker also received support from the Gottlieb-Daimler and Karl-Benz Stiftung. W. Broecker also receives support from Lawrence Livermore National Laboratory. This is Lamont-Doherty Earth Observatory contribution number 5198 .

\section{References}

Baumgartner, A., and E. Reichel, The World Water Balance. R. Oldenbourg Verlag, München, Germany, 1975 . 
Broecker, W. S., The great ocean conveyor, Oceanography, 4, 79-89, 1991.

Broecker, W. S., and G. H. Denton, The role of ocean-atmosphere reorganizations in glacial cycles, Geochim. Cosmochim. Acta, 53, 2465-2501, 1989.

Broecker, W. S., T.-H. Peng, J. Jouzel, and G. L. Russell, The magnitude of global fresh-water transports of importance to ocean circulation, Clim. Dyn., 4, 73-79, 1990.

Bryan, F., High-latitude salinity effects and interhemispheric thermohaline circulations, Nature, 323, 301304, 1986.

Chamberlin, T. C., On a possible reversal of the deepsea circulation and its influence on geologic climates, J. Geol., XIV (5), 363-373, 1906.

Dansgaard, W., J. W. C. White, and S. J. Johnsen, The abrupt termination of the younger dryas climate event, Nature, 339, 1989.

Dickson, R. P., J. Meincke, S.-A. Malmberg, and A. J. Lee, The "Great Salinity Anomaly" in the northern North Atlantic 1968-1982, Prog. Oceanogr., 20, 103151, 1988.

Gordon, A. L., Interocean exchange of thermocline water, J. Geophys. Res., 91, 5037-5046, 1986.

Gordon, A. L., and A. R. Piola, Atlantic Ocean upper layer salinity budget, J. Phys. Oceanogr., 13, 1293$1300,1983$.

Han, Y. J., and S. W. Lee, An analysis of monthly mean wind stress over the global ocean, Mon. Weather Rev., 111, 1554-1566, 1983.

Hansen, J., G. Russell, D. Rind, P. Stone, A. Lacis, S. Lebedeff, R. Ruedy, and L. Travis, Efficient threedimensional global models for climate studies: Models I and II, Mon. Weather Rev., 111, 609-662, 1983.

Hughes, T. M. C., and A. J. Weaver, Multiple equilibria of an asymmetric two-basin ocean model, $J$. Phys. Oceanogr., 1993, in press.

Lehman, S. J., and L. D. Keigwin, Sudden changes in North Atlantic circulation during the last deglaciation, Nature, 356, 757-762, 1992.

Levitus, S., Climatological atlas of the world ocean, NOAA Prof. Pap. 13, 1982.

Maier-Reimer, E., and U. Mikolajewicz, Experiments with an OGCM on the cause of the Younger Dryas, in Oceanography 1988, edited by A. Ayala-Castanares, W. Wooster, , and A. Yañez Arancibia, pp. 87-100, Universidad Nacional Autónoma de México Press, México, D.F., 1989.

Manabe, S., and R. J. Stouffer, Two stable equilibria of a coupled ocean-atmosphere model, J. Clim., 1, 841-866, 1988.

Marotzke, J., and J. Willebrand, Multiple equilibria of the global thermohaline circulation, J. Phys. Oceanogr., 21, 1372-1385, 1991.

Mikolajewicz, U., and E. Maier-Reimer, Internal secular variability in an ocean general circulation model, Clim. Dyn., 4, 145-156, 1990.

Oort, A. H., Global atmospheric circulation statistics, 1958-1973, NOAA Prof. Pap. 14, 180 pp., U.S. Gov. Print. Office, Washington, D.C., 1983.
Schlosser, P., G. Bönisch, M. Rhein, and R. Bayer, Reduction of deepwater formation in the Greenland Sea during the 1980s: Evidence from tracer data, Science, 251, 1054-1056, 1991.

Schmitt, R. W., P. S. Bodgen, and C. E. Dorman, Evaporation minus precipitation and density fluxes for the North Atlantic, J. Phys. Oceanogr., 19, 1208-1221, 1992.

Stocker, T. F., and D. G. Wright, Rapid transitions of the ocean's deep circulation induced by changes in surface water fluxes, Nature, 351, 729-732, 1991.

Stocker, T. F., D. G. Wright, and W. S. Broecker, The influence of high-latitude surface forcing on the global thermohaline circulation, Paleoceanography, 7, 529$541,1992$.

Stommel, H. M., Asymmetry of interoceanic freshwater and heat fluxes, Proc. Natl. Acad. Sci. U.S.A., 77, 2377-2381, 1980.

Stommel, H. M., and G. T. Csanady, A relation between the $T-S$ curve and global heat and atmospheric water transports, J. Geophys. Res., 85, 495-501, 1980.

Toggweiler, J. R., and B. Samuels, Is the magnitude of the deep outflow from the Atlantic Ocean actually governed by southern hemisphere winds?, in The Global Carbon Cycle, edited by M. Heimann, 303331, Springer-Verlag, New York, 1993.

Walin, G., The thermohaline circulation and the control of ice ages, Palaeogeogr. Palaeoclimatol. Palaeoecol., 50, 323-332, 1985.

Warren, B. A., Why is no deep water formed in the North Pacific?, J. Mar. Res., 41, 327-347, 1983.

Weaver, A. J., J. Marotzke, P. F. Cummins, and E. S. Sarachik, Stability and variability of the thermohaline circulation, J. Phys. Oceanogr., 23, 41-60, 1993.

Weyl, P. K., The role of the oceans in climatic change: A theory of the ice ages, Meteorol. Monogr., 8, 37-62, 1968.

Wright, D. G., and T. F. Stocker, A zonally averaged ocean model for the thermohaline circulation. part I: Model development and flow dynamics., $J$. Phys. Oceanogr., 21, 1713-1724, 1991.

Wright, D. G., and T. F. Stocker, Sensitivities of a zonally averaged global ocean circulation model, J. Geophys. Res., 97, 12707-12730, 1992.

Wüst, G., Die Stratosphäre, Wiss. Ergeb. Dtsch. Atl. Exped. Meteor 1925-1927, 6, 109-288, 1935.

Wüst, G., and A. Defant, Atlas zur Schichtung und Zirkulation des Atlantischen Oceans, Schnitte und Karten von Temperatur, Salzgehalt und Dichte, Wiss. Ergeb. Dtsch. Atl. Exped. Meteor 1925-1927, 6, 103 pp., 1936.

Yin, F. L., I. Y. Fung, and C. K. Chu, Equilibrium response of ocean deep-water circulation to variations in Ekman pumping and deep-water sources, J. Phys. Oceanogr., 22, 1129-1157, 1992.

Zaucker, F., Observed versus modelled freshwater fluxes and their impact on the global thermohaline circulation, $\mathrm{Ph} . \mathrm{D}$. thesis, Institute for Environmental Physics, University of Heidelberg, INF 366, $6900 \mathrm{Hei}-$ delberg, Germany, 1992. 
Zaucker, F., and W. S. Broecker, The influence of atmospheric moisture transport on the fresh water balance of the atlantic drainage basin: General circulation model simulations and observations, J. Geophys. Res., 97, 2765-2773, 1992.

F. Zaucker, NASA Goddard Institute for Space Studies, 2880 Broadway, New York, N.Y. 10025.

(e-mail: cdfwz@r2d2.giss.nasa.gov)
T. F. Stocker, Physics Institute, University of Bern, Sidlerstr. 5, CH-3012 Bern, Switzerland.

W. S. Broecker, Department of Geochemistry, LamontDoherty Earth Observatory, Columbia University, Palisades, N.Y. 10964.

(Received March 8, 1993; revised December 4, 1993; accepted December 20, 1993.) 